\title{
Dental implant treatment: Experience in a tertiary hospital in Nigeria
}

\author{
Agboghoroma Okeoghenemaro Gloria ${ }^{1}$, Enabulele Joan Emien ${ }^{2 *}$ and Omo Julie Omole ${ }^{2}$ \\ ${ }^{1}$ Restorative unit, Dental Department National Hospital Abuja, Nigeria \\ ${ }^{2}$ Department of Restorative Dentistry, School of Dentistry, University of Benin, Benin City, Nigeria
}

\begin{abstract}
Aims: To characterise the types of implants and implant supported restorations placed in a tertiary hospital as well as determine the outcome of the implant treatment.

Materials and methods: This was a retrospective study of patients who received dental implants. The socio-demographic characteristics, smoking and alcohol use, medical history, reason for missing teeth, missing teeth, type of implant, surgery, adjunctive procedure, postoperative complaints and outcome at one week, 6 months and one year after implant surgery.

Results: Data of 61 patients who received 111 implants were utilized for the study. The maxillary arch received $61.3 \%$ and $55.7 \%$ of the implants were single tooth implants. Anterior teeth made up $63.1 \%$ of the dental implants. Most (74.8\%) were conventional implants while $25.2 \%$ were immediate implants. Cylindrical implants were placed in $76.6 \%$ of cases while tapered implants were placed in $23.4 \%$. Single crown was provided in $59.5 \%$ of the cases while fixed partial dentures were provided in $40.5 \%$. At 7 days post-op $81.1 \%$ of the cases had no complaints. At 6 months review $65.8 \%$ had no notable complications. At one-year review, favorable clinical outcome was recorded in $75.7 \%$ of the cases while favorable radiographic outcome was recorded in $72.1 \%$ of the cases. Clinically, periimplantitis was observed in $9.0 \%$ of cases.
\end{abstract}

Conclusions: The survival of implants can be influenced by site of placement, position of placement, arch and type of implant while not being compromised by the medical conditions, age gender, oral hygiene status prior to implant placement, adjunctive procedure and type of surgery.

\section{Introduction}

Dental implants provide predictable treatment outcome for the replacement of missing teeth that were not previously available [1] The increase in its awareness as a replacement for missing teeth has led to an increase in its demand [2]. This increased patient awareness, expectations and demands have led to an explosion of the dental implant market [3].

The positive clinical results of implant treatments have been demonstrated in several studies [1,4], this ultimately have impacted positively on the quality of life of patients. The burden of tooth loss includes decreased satisfactory function, decreased social confidence, disturbed self-image, and self-esteem [5]. Tooth loss may be partial or complete and there are various options available for its management, these include the removable partial denture, fixed partial dentures and the use of dental implants. Dental implants offer the best replacement option because of its superior long-term results, better retention, stability, functional efficiency and better quality of life [6]. It dependably replaces missing teeth both aesthetically and functionally [7].

Dental implants have become the standard of care for some cases of tooth loss such as the single tooth replacement because it is predictable and more conservative than other forms of treatment such as crowns and bridges [8]. More patients are becoming aware of the use of dental implant as a form of tooth replacement therapy as a result of the unlimited information from the web and this has increased the demand for dental implants [9].

Implant therapy although accepted as a predictable treatment option for replacing missing teeth [10] is still yet to be a readily available treatment in developing economies like Nigeria. Some studies have been done in this clime as regard implant treatment of patients with good outcome $[2,11]$ however, these studies were done majorly in the South western region, there still appears to be paucity of studies in other regions hence the need for this study which characterised the types of implants and implant supported restorations placed in a tertiary hospital in the Federal Capital Territory (FCT) of Nigeria as well as determine the outcome of the implant treatment.

\section{Methodology}

This was a retrospective study of all patients who received dental implants at the Restorative Unit, Dental and Maxillofacial Department of the National Hospital FCT, Abuja from 2015 to 2020. All case notes numbers of patients who received dental implants over the study period were identified and the records available from the identified cases were retrieved. All the range of implant treatment (surgery and final prosthetic appliance) were placed by the first author. The implants were placed in accordance with manufacturer's instructions. The following information using a proforma were obtained: age, gender, marital status,

*Correspondence to: Joan Enabulele, Department of Restorative Dentistry, University of Benin, School of Dentistry, Benin City, Edo State, Nigeria, Tel: +2348037275813; E-mail: emien.enabulele@uniben.edu

Key words: dental implant, experience, treatment, outcome

Received: December 01, 2020; Accepted: December 31, 2020; Published: January 06, 2021 
occupation, smoking history, alcohol consumption, medical history of hypertension, diabetes mellitus, and any other medical condition of interest, reason for missing teeth, missing teeth replaced with implant, type of implant placed, type of surgery, adjunctive procedure like sinus lift, guided bone regeneration, postoperative complaints at one week recall after implant surgery, type of prosthesis provided and outcome of implant placement at one year recall. Specific deficiencies of the peri-implant tissues such as presence of gingival inflammation, periimplantitis, soft tissue defect, extrusion of bone substitute and specific deficiencies of the restoration such as implant fracture, loss of implant, mobile crown/cement failure, fractured abutment were recorded.

All data collated was analysed using the IBM SPSS version 21.0 (Chicago, IL, USA) and Microsoft Excel 2010. The analysis carried out were descriptive statistics with frequency and percentages used to describe the categorical variables while the mean and standard deviation of continuous variables was obtained. Chi-square test was used to determine association between categorical variables with the level of statistical significance set at $95 \%$ confidence interval.

\section{Results}

A total of 78 patients received dental implants over the study period however only 61 case notes were available and retrieved and the 61 patients received 111 implants. The patients age ranged from 19 years to 76 years with a mean age of $50.08 \pm 13.54$ years and the most prevalent age group was 41-50years making up $24.6 \%$ (95\% confidence interval 14.8 36.1 ) of the patients studied. The least represented age group were those 30 years and younger accounting for $9.8 \%$ (95\% confidence interval 3.3-18.0) of the study population. There was a male predominance with males accounting for $54.1 \%$ of the study population. Skilled workers and professionals made up $62.3 \%$ and $26.2 \%$ of the study population respectively and $80.3 \%$ were married (Table 1 ).

Majority $80.3 \%$ (95\% confidence interval 70.5-90.2) of the patients had fair oral hygiene while $8.2 \%$ (95\% confidence interval 1.6-16.4) and $11.5 \%$ (95\% confidence interval 3.3-19.7) had good and poor oral hygiene respectively prior to implant treatment.

More than half, $60.7 \%$ (95\% confidence interval 49.2-72.1) had no medical condition of note while the remaining 39.3\% (95\% confidence interval 27.9-50.8) had a positive medical history. Hypertension was recorded in (12) 50.0\% (95\% confidence interval 33.3-70.8) of those with a positive medical history. Organ transplant and retroviral disease was recorded in $2(8.3 \%)$ each. Hypertension in combination with diabetes mellitus was noted in $3(12.5 \%)$ of those that had positive medical history. Other medical conditions recorded were peptic ulcer diseases 2(8.3\%), epileptic seizure 1 (4.2\%), Parkinson's disease $1(4.2 \%)$ and allergies $1(4.2 \%)$.

The most prevalent reason for seeking dental implant treatment was replacement of missing tooth represented by $56.8 \%$ (95\% confidence interval 48.6-64.9), followed by broken teeth 19.8 (95\% confidence interval 12.6-27.9) and badly broken-down teeth (95\% confidence interval2.7-12.6). The least prevalent reason was inability to chew $0.9 \%$ (Figure 1).

The most prevalent cause of the missing teeth that were replaced with dental implants was trauma accounting for $36.0 \%$ (95\% confidence interval 27.0-45.0), followed by sequelae of dental caries accounting for $28.8 \%$ (95\% confidence interval 20.7-37.8). Failed root canal treatment was noted in $13.5 \%$ (95\% confidence interval 7.2-20.7) of the missing teeth. Fractured bridge abutment was observed in 5.4\% (95\% confidence interval 1.8-9.9) of the cases and loss of teeth following periodontal disease was recorded in $8.1 \%$ (95\% confidence interval 3.6-13.5) of the cases (Figure 2).

Of the 111 teeth replaced with dental implant, the maxillary arch received $61.3 \%$ (95\% confidence interval 52.3-70.3) of the implants while the mandibular arch received the remaining $38.7 \%(95 \%$ confidence interval 29.7-47.7). More than half (55.7\%) of the patients received a single implant, $29.5 \%$ received 2 implants, $6.6 \%$ received 3 implants and the remaining $8.2 \%$ received more than 3 implants.

Anterior teeth made up 63.1\% (95\% confidence interval 54.1-71.2) of the teeth that received dental implant while posterior teeth made up the remaining $36.9 \%$ (95\% confidence interval 28.8-45.9). The most frequently replaced tooth with dental implant were the central incisors $48.6 \%$ (95\% confidence interval 39.6-57.7) followed by the first molars $12.6 \%$ (95\% confidence interval 6.3-19.8) and second molars $11.7 \%$ (95\% confidence interval 6.3-19.8). the tooth with the least representation were the canines 3.6 (95\% confidence interval 0.9-7.2) and the first premolars $4.5 \%$ (95\% confidence interval 0.9 9.0) (Figure 3).

With regards to the type of implant placed $74.8 \%$ (95\% confidence interval 65.8-82.9) received conventional implant while $25.2 \%$ (95\% confidence interval 17.1-34.2) received immediate implants. Cylindrical implants were placed in $76.6 \%$ of cases while tapered implants were placed in $23.4 \%$. Adjunct procedures were performed in $49.5 \%$ of cases with the most prevalent adjunct procedure being guided bone regeneration (94.5\%). Single crown was provided in $59.5 \%$ of the cases while fixed partial dentures were provided in $40.5 \%$ (Table 2).

Table 1. Sociodemographic characteristics of the patients

\begin{tabular}{|c|c|c|c|}
\hline Characteristics & $\begin{array}{c}\text { Frequency } \\
\mathbf{n = 6 1}\end{array}$ & Percent & $\mathbf{9 5 \%}$ Confidence interval \\
\hline Age group (years) & & & \\
$\leq 30$ & 6 & 9.8 & $3.3-18.0$ \\
$31-40$ & 9 & 14.8 & $6.6-23.0$ \\
$41-50$ & 15 & 24.6 & $14.8-36.1$ \\
$51-60$ & 19 & 31.1 & $19.7-44.3$ \\
$\geq 60$ & 12 & 19.7 & $9.8-31.1$ \\
\hline Gender & & & \\
Male & 33 & 54.1 & $41.0-67.2$ \\
Female & 28 & 45.9 & $32.8-59.0$ \\
\hline Occupation & & & \\
Professional & 16 & 26.2 & $16.4-37.7$ \\
Skilled worker & 38 & 62.3 & $0.0-73.8$ \\
Unskilled worker & 1 & 2.6 & $3.3-18.0$ \\
Dependent & 6 & 9.8 & \\
\hline Marital status & & & $9.8-29.5$ \\
Single & 12 & 19.7 & \\
Married & 49 & 80.3 & \\
\hline & & & \\
\hline
\end{tabular}

Table 2. Characteristics of implant placed

\begin{tabular}{|c|c|c|c|}
\hline Characteristics & $\begin{array}{c}\text { Frequency } \\
\mathbf{n = 1 1 1}\end{array}$ & Percent & $\mathbf{9 5 \%}$ Confidence interval \\
\hline $\begin{array}{c}\text { Type of implant } \\
\text { Conventional implant }\end{array}$ & 83 & 74.8 & $65.8-82.9$ \\
Immediate implant & 28 & 25.2 & $17.1-34.2$ \\
\hline $\begin{array}{c}\text { Implant design } \\
\text { Cylindrical }\end{array}$ & 85 & 76.6 & $69.4-83.8$ \\
Tapered & 26 & 23.4 & $16.2-30.6$ \\
\hline $\begin{array}{c}\text { Adjunct procedure } \\
\text { Yes }\end{array}$ & 55 & 49.5 & $40.5-59.4$ \\
No & 56 & 50.5 & $40.6-59.5$ \\
\hline $\begin{array}{c}\text { Super structure } \\
\text { placed }\end{array}$ & & & \\
Single crown & 66 & 59.5 & $50.5-68.5$ \\
Fixed partial denture & 45 & 40.5 & $31.5-49.5$ \\
\hline
\end{tabular}




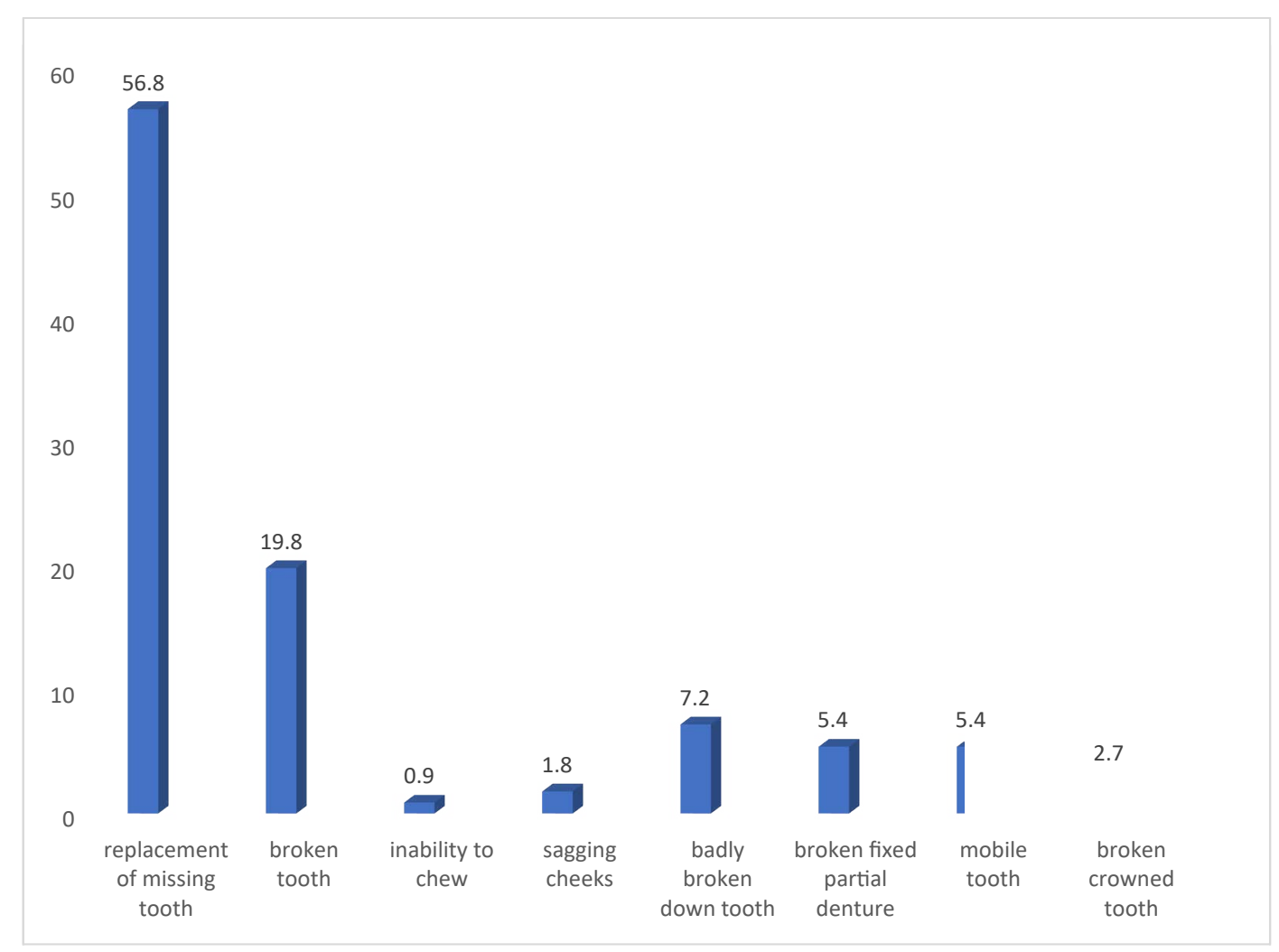

Figure 1. Reason for seeking dental implant treatment

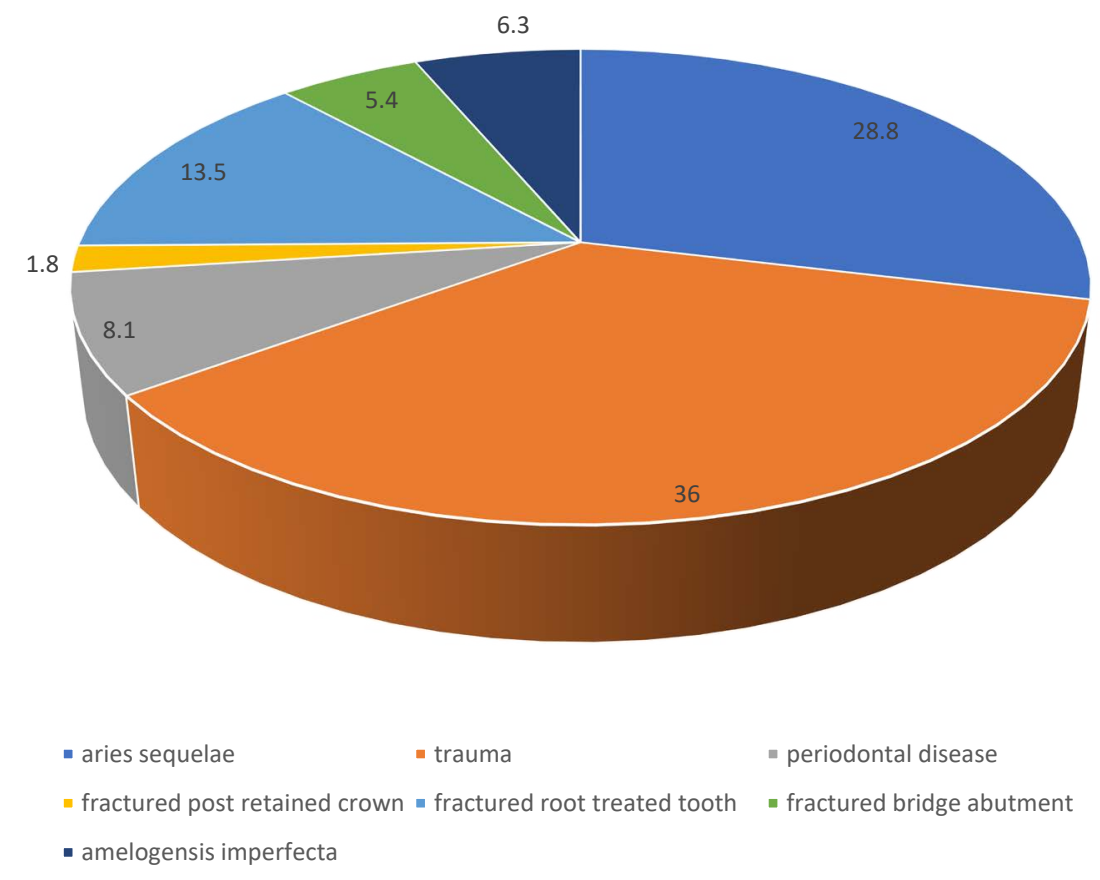

Figure 2. Reason for tooth loss 
Guided bone regeneration made up $94.5 \%$ of the adjunct procedure carried out while soft tissue augmentation, bone augmentation, and open flap curettage accounted for $1.8 \%$ each.

At 7 days post-op $81.1 \%$ of the cases had no complaints, $4.5 \%$ had paraesthesia and inflammation and swelling around implant surgery site was observed in $2.7 \%$ of the cases.

At 6 months review $65.8 \%$ had no notable complications. Periimplantitis was the most prevalent complication recorded (34.2\%), followed by failed osseointegration $21.1 \%$, implant fracture $15.8 \%$, paraesthesia $13.2 \%$, soft tissue defect and loss of implant $5.3 \%$ each. All the restorations were cement retained

At one-year review, favorable clinical outcome was recorded in $75.7 \%$ of the cases while favourable radiographic outcome was recorded in $72.1 \%$ of the cases. Clinically, periimplantitis was observed in $9.0 \%$ of cases, soft tissue defect in $2.7 \%$, fractured implant in $5.4 \%$, loss of implant in $2.7 \%$, fractured abutment and mobile crown in $0.9 \%$ each of the cases. Radiographically, complete failure of osseointegration was observed in $3.6 \%$ of the cases, partial osseointegration in $16.2 \%$ and explantation in $8.1 \%$ of the cases.

Overall, 76 implants had neither clinical or radiographic complications giving an overall favorable outcome of $69.1 \%$. The age group of the patients, gender, presence of medical history, oral hygiene status prior to placement of the dental implant, type of surgery whether conventional or immediate and performance of adjunct procedures had no significant influence of the outcome of the dental implant treatment at one year post operatively.

The type of tooth whether anterior or posterior was associated with the outcome of the dental implant with a higher proportion of posterior teeth exhibiting more favorable outcome $(\mathrm{P}=0.015)$. Similarly, implants placed in the mandibular arch had more favorable outcome compared to those placed in the maxilla and this was statistically significant $(p=0.025)$. Furthermore, a higher proportion of tapered (root form) implants had favorable outcome compared to the cylindrical implants $(\mathrm{p}=0.05)$ (Table 3$)$.

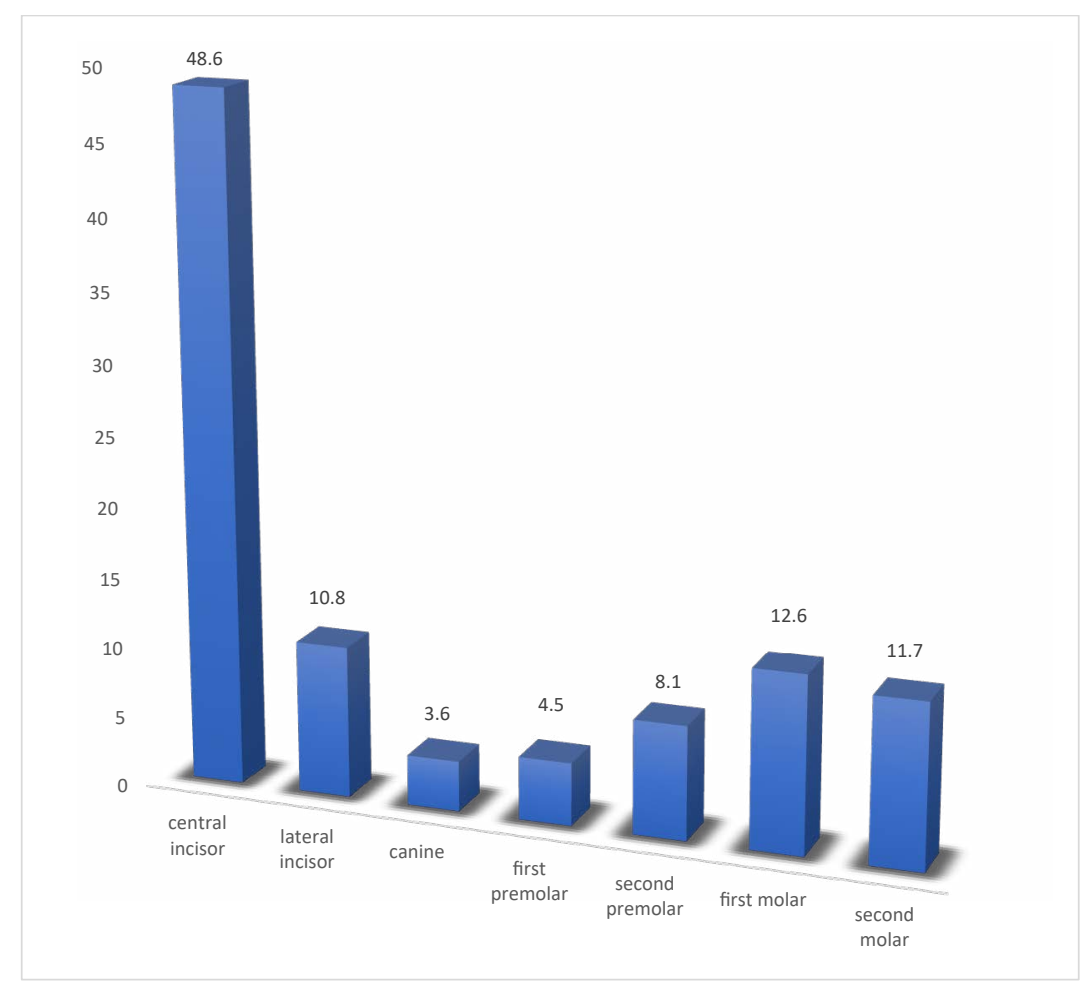

Figure 3. Distribution of teeth replaced with dental implant

Table 3. Association between implant site, arch and implant design and outcome one year post-operatively

\begin{tabular}{|c|c|c|c|c|}
\hline \multirow{2}{*}{ Characteristics } & \multicolumn{2}{|c|}{ Outcome } & \multirow{2}{*}{ Total } & \multirow{2}{*}{ Pvalue } \\
\hline & Favorable & Unfavorable & & \\
\hline $\begin{array}{c}\text { Implant site } \\
\text { Anterior region } \\
\text { Posterior region }\end{array}$ & $\begin{array}{l}42(60.9) \\
34(82.9)\end{array}$ & $\begin{array}{c}27(39.1) \\
7(17.1)\end{array}$ & $\begin{array}{l}69(100.0) \\
41(100.0)\end{array}$ & 0.015 \\
\hline $\begin{array}{c}\text { Arch } \\
\text { Maxillary } \\
\text { Mandibular }\end{array}$ & $\begin{array}{l}41(61.2) \\
35(81.4)\end{array}$ & $\begin{array}{c}26(38.8) \\
8(18.6)\end{array}$ & $\begin{array}{l}67(100.0) \\
43(100.0)\end{array}$ & 0.025 \\
\hline $\begin{array}{c}\text { Implant design } \\
\text { Cylindrical } \\
\text { Tapered (root form) }\end{array}$ & $\begin{array}{l}54(64.3) \\
22(84.6)\end{array}$ & $\begin{array}{c}30(35.7) \\
4(15.4)\end{array}$ & $\begin{array}{l}84(100.0) \\
26(100.0)\end{array}$ & 0.05 \\
\hline Total & $76(69.1)$ & $34(30.9)$ & $110(100.0)$ & \\
\hline
\end{tabular}




\section{Discussion}

Implant treatment, a not so nouveau protocol has gradually gained acceptance with the Nigerian populace. Patients and clinicians are embracing it as the new normal for replacement of missing teeth arising from trauma, sequelae of dental caries, failed root canal treatments etc apart from bridges and removable prostheses. This study describes the experience of dental implant treatment in a tertiary hospital in Nigeria.

The age range of patients (19 years to 76 years) in this study is similar to that reported in a previous Nigerian study [2] and an Australian study [12]. The mean (standard deviation) age of the patients $50.08 \pm 13.54$ years noted in this study is close to the 51.5years reported in Australia [12] but lower than the $61.4 \pm 12.2$ years and $60.6 \pm 12.7$ years recorded in previous studies $[10,13]$ and higher than the $48.4 \pm 16.6$ years recorded in a previous Nigerian study [2]. The most prevalent age group was 41-50years in this study, a finding different from the most prevalent age group of 60-69years reported in previous studies [12,14]. This shows that dental implant treatment cuts across a wide age range for varying reasons.

A male preponderance was observed in this study a finding in contrast to that reported in the United States [10], Germany [13] and Korea [14] where there was a female preponderance but similar to previous Nigerian studies [2,11]. The preponderance of males in this study may be attributed to the occupation of the male participants who tend to be easily given to trauma related events and contact sports than women leading to loss of teeth and possible more earning power of males in Nigeria as dental implants are not so cheap with females showing tendency to go for less expensive or cost-effective tooth replacement options in Nigeria [15].

Despite the high cost of dental implant, the occupation of the patients reviewed in this study shows that dental implant treatment protocol is not exclusive to the elites as there were skilled workers, professionals of varying cadre and otherwise. This may be because the center where this study was done allowed for dental implant treatment cost to be made in installments.

Majority of the patients in this study had fair oral hygiene a finding different from a previous report where majority of the patients had good oral hygiene [14]. Oral hygiene is an important factor in patient assessment prior to implant placement however the pre-operative oral hygiene status of a patient may not reflect on the prognosis. Although only few absolute contraindications to implant treatment exist [16], it has been thought that patients with a periodontal history are at higher risk for potential peri-implantitis leading to late implant failure [17].

The finding in this study portrayed more than half of the patients had no prior medical condition of note similar to a previous study [2]. Diabetes was recorded in this study a finding which corroborates a previous report of diabetics receiving dental implants [13]. Also, Hypertension alone and Hypertension in combination with diabetes mellitus were some of the medical conditions recorded in this study a finding similar to a previous study [2]. These medical conditions are not absolute contra-indications for dental implant treatment [18] as the level of evidence indicative of absolute and relative contraindications for implant therapy due to systemic diseases is low [19] making it feasible to perform the implant surgery with successive outcomes.

The most prevalent reason for implant placement was missing teeth following trauma (36.0\%), a finding similar to that reported in previous studies $[2,10]$, followed by sequelae of dental caries accounting for $28.8 \%$ (95\% confidence interval 20.7-37.8). The prevalence of failed root canal treatment as a reason for implant treatment observed in this study
(13.5\%) was far lower than that recorded in a study in the United States where failed endodontic treatment was noted in $25.1 \%$ of the study population [10] and a Nigerian study that recorded 21.74\% [2].

There was a higher proportion of implants placed in the maxillary arch compared with the mandibular arch. This is in contrast to a previous study that recorded a higher proportion of implants placed in the mandibular arch [14] and another study that noticed no difference in the frequency of implant placement in the maxillary or mandibular arch [10] but in agreement with a previous Nigerian study a German study $^{13}$ and an Australian study [12]. The pattern of placement of implant by arch reflects the pattern of tooth loss in Nigeria where maxillary teeth are lost more commonly compared to mandibular teeth [20,21].

Most of the patients received a single implant a finding in agreement with a previous report that had $47.8 \%$ of the study population receiving a single implant [2]. This may be related to previous reports that demonstrated that implant-supported single-tooth replacement is a predictable procedure with higher survival rates $[22,23]$.

Anterior teeth made up majority of the dental implants placed in this study. This is contrary to a German [13] and Korean [14] study were posterior teeth were in the majority. The most frequently replaced tooth with dental implant in this study were the central incisors followed by the first molars and second molars. A pattern similar to a previous report [2] but different from a report in the United States where the highest number of implants were placed in the mandibular molar followed by the maxillary premolar [10]. The tooth with the least representation in this study were the canines a finding similar to previous studies $[2,10,14]$. The pattern of dental implant placement seems to be a reflection of pattern of tooth loss with canine having the least representation. This can be attributed to the fact that the canines are the least prevalent missing teeth $[20,21]$.

With regards to the type of implant placed, a far higher proportion of the implants placed were conventional implants compared to immediate implants. This distribution is different from that reported in a previous study [2] where only $4.8 \%$ of the implants placed were immediate implants.

Cylindrical implants were used more in this study compared with tapered (root form) implants. The reverse was the case in a previous study were more root-form implants were placed compared to the cylindrical form [10]. This difference may be due to the availability of implant form.

Guided bone regeneration was the most common adjunct procedure performed in this study which is different from the most prevalent adjunct procedure (bone grafts) placed in a previous study [10]. Guided bone regeneration is a procedure that assists with bone regeneration and entails the placement of mechanical barriers to protect blood clots and isolate the bone from surrounding connective tissue, by so doing encourages bone forming cells access for bone regeneration $[24,25]$. This is done to reduce or prevent post-extraction bone resorption to preserve ridge integrity [26]. In this study it was observed that guided bone regeneration constituted a major proportion of the adjunct procedures (94.5\%), this observation contradicts that of a study done among private clinics where $35.9 \%$ was recorded, however the soft tissue augmentation was slightly more than that observed in this study [27].

Single unit restoration was provided in more than half of the cases in this study. This is far lower than the $83.6 \%$ recorded for single unit 
restoration in a previous study [10] but close to the $56.93 \%$ reported in another study [12]. Dental implants are the standard of care for single missing tooth as placement of a single implant prevents the needless destruction of sound teeth adjacent to the edentulous area as would be required for a fixed partial denture, as well as avoids the pulpal, periodontal, and endodontic complications of the supporting abutments associated with the fixed dental prosthesis [28], hence the high prevalence of single unit restoration.

Despite its high success rate, dental implant treatment is not free of complications [29]. Majority of the patients had no complaint within the first week post-operatively. The most common complaint within a week of the dental implant placement was paraesthesia, inflammation and swelling around implant surgery site. This can be considered as early implant complications arising immediate post operatively.

Peri-implantitis is one of the most common biological complications affecting functional implants [30], associated with pocket formation and peri-implant bone loss [31] and a major cause of implant failure. At 6 months follow-up review, peri-implantitis was recorded as the most prevalent complication, this contradicts those of other studies [32,33]. This could be the result of limited number of patients that reached the follow-up period in one of the studies [32]. Other complications encountered in this study were failed osseointegration, implant fracture, paraesthesia, soft tissue defect and implant loss which compares with that of an earlier study [34].

Implant fracture has been observed to be one of the major reasons for late failure [29], however, in this study it was observed 6 months after implant surgery before loading of the implant in $15.8 \%$ of the cases with complications. Although the incidence of implant fractures may be low, it invariably affects the patient and also clinician [29].

All the restorations in this study were cement retained this is in contrast to a previous study where $93.1 \%$ of the restorations were cement retained and $6.9 \%$ were screw retained [10]. This is due to the type of implant available for use among the patients in this study.

Some of the notable reasons recorded as causes of implant failure include soft tissue defect, the peri-implant soft tissue are more vulnerable compared with the soft tissue around the natural teeth, this is due to deeper probing depth, weaker connective tissue attachment, faster inflammatory expansion and reduced vascular supply making the soft tissue susceptible to bacteria build-up and subsequent soft tissue defect [35]. Fractured implants could be caused by biomechanical overload leading to metal fatigue or lack of passive fit of the prosthetic screw [36,37].

At one-year review, favorable clinical outcome was recorded in $75.7 \%$ of the cases while favourable radiographic outcome was recorded in $72.1 \%$ of the cases. This is lower than that reported in a previous Nigerian study at one year follow up [2]. Radiographically, complete failure of osseointegration was observed in $3.6 \%$ of the cases, partial osseointegration in $16.2 \%$ and explantation in $8.1 \%$ of the cases. It has been postulated that absence of intimate bone to implant connection results in failure of osseointegration [13].

The prevalence of periimplantitis of $9.0 \%$ observed in this study is lower than reported in previous studies which ranged from $4.7 \%$ to $47.1 \%{ }^{38-40}$ This difference may be due to the timing of review as this study was a one-year review while the previous studies the review ranged from 6 to 9 years. It is possible that if the patients in this study are reviewed much later the prevalence may increase.
Overall, 76 implants had neither clinical nor radiographic complications giving an overall favorable outcome of $69.1 \%$. The gender, presence of medical history, oral hygiene status prior to placement of the dental implant, and performance of adjunct procedures had no significant influence on the outcome of the dental implant treatment at one year post operatively. A previous report showed no association between the presence of diabetes and osseointegration despite diabetes being a metabolic disease that affects blood circulation [13].

Although, age has been considered as one of the important prognostic factors in implant success [41,42], the age of the patients in this study did not influence the outcome of the implant treatment.

The type of surgery whether conventional or immediate was not associated with increased risk in implant failure. A finding different from that reported in a previous study were immediate versus delayed implant placement were associated with an increased risk of implant failure [10]. However, the type of tooth whether anterior or posterior was associated with the outcome of the dental implant a finding similar to a previous report [10].

Mandibular implants had more favorable outcome when compared with the maxillary implant. This corroborates reports of other studies and it appears to be connected to the quality and quantity of the bones $[43,44]$ but contradicts another study that reported higher prevalence of periimplantitis in mandibular implants [38].

It has been reported that the insertion torque of tapered implants is more than that of cylindrical implants resulting in better primary stability in tapered implants [45]. Furthermore, the screw threads are different in both types of implants whereby the thread geometry of tapered implants leads to a higher surface area in contact with host tissue $[45,46]$. This may be the reason for the observation in this study which was also reported in other studies $[45,46]$. However, this contradicts the reports of other studies where there was no difference in the outcome based on implant shape $[47,48]$.

\section{Conclusion}

Anterior teeth implant, conventional implant, cylindrical implant and single tooth implant with single crown were prevalent. Review of patients is critical to implant success. Recall visits as early as 7 days post implant surgery is recommended as this will help to address any immediate issues. 6 months recall visits are also very important to review cases before placement of prosthetic restoration. Recall visit 1-year post implant surgery is critical as complications can be quickly identified and addressed to enhance longevity of the implant. Complications can arise from the implant fixture, surrounding soft tissue and prosthetic appliance. The survival of implants can be adduced to be influenced by site of placement, position of placement, arch and type of implant while not being compromised by the medical conditions of the patients, age of the patient, gender, oral hygiene status prior to implant placement, adjunctive procedure and type of surgery whether immediate or conventional.

Clinical implications: Single tooth implant is a viable replacement option for missing teeth. The type of implant (whether cylindrical or tapered) readily available influences the type of implant placed. Immediate implants are acceptable as a type of implant placement.

There is need for continuous monitoring and follow up of dental implant patients right from the first week of placement and 6 months post implant placement so that early complications can be identified and managed where possible. It is also recommended that 1 -year follow up care be carried out for patients with dental implant. 


\section{Source(s) of support}

The authors were solely responsible for sponsoring this research.

\section{Conflicts of interest}

The authors declare no conflicts of interest.

\section{References}

1. Simonis P, Dufur T, Tenenbaum H (2010) Long term implant survival and success: a 10-16year follow-up of non-submerged dental implants. Clin Oral Implants Res 21:772-777. [Crossref]

2. Ajayi DM, Abiodun-Solanke IMF, Gbadebo SO, Fashola AO, Dosumu OO, et al. (2014) Dental implant treatment at a Nigerian Teaching Hospital. J West Afr Coll Surg 4: 89-99.

3. Enabulele JE, Omo JO (2020) Teaching of dental implantology to undergraduate dental students: the Nigerian experience. Eur J Dent Educ 24: 476-482. [Crossref]

4. Zarb GA, Schmutt A (1995) Implant prosthodontic treatment options for the edentulous patient. J Oral Rehabil 22: 661-671. [Crossref]

5. Kashbour WA, Rousseau NS, Ellis JS, Thomason JM (2015) Patients' experience of dental implant treatment: A literature review of key qualitative studies. J Dent 43: 789797.

6. Nallaswamy VD, Karthikeyan R, Vinaya B. New Delhi, Textbook of prosthodontics pp 720-730.

7. Wang H, Shotwell JL, Itose T, Neiva RF (2005) Multidisciplinary treatment approach for enhancement of implant aesthetics. Implant Dent 14: 21-29. [Crossref]

8. Mayer TM, Hawley CE, Gunsolley JC, Feldman S (2002) The single tooth implant: A viable alternative to single tooth replacement. J Periodontol 73: 687-693. [Crossref]

9. Adeyemo WL, Akeredolu PA, Oderinu HO, Olorunfemi BO (2007) Dental implant education in Nigeria: A curriculum guide. Niger Postgrad Med J 14: 247-251.

10. Da Silva JD, Kazimiroff J, Curro FA, Thompson VP, Vena DA, et al. (2014) Outcomes of implants and restorations placed in general dental practices. J Am Dent Assoc. 2014;145:704-713.

11. Akeredolu PA, Adeyemo WL, Omololu OB, Karunwi O (2010) Implant restoration of partially edentulous ridges: A review of 121 Nigerian patients. Implant Dentistry 19: 65-73. [Crossref]

12. Duong A, Dudley J (2018) Twenty years analysis of implant treatment in an Australian dental clinic. Aust Dent J 63: 177-186.

13. Krisam J, Ott L, Schmitz S, Klotz A, Seyidaliyeva A, et al. (2019) Factors affecting the early failure of implants placed in a dental practice with a specialisation in implantology - a retrospective study. BMC Oral Health 19: 208-211. [Crossref]

14. Ahn D, Kim H, Joo J, Lee J (2019) Prevalence and risk factors of peri-implant mucositis and peri-implantitis after at least 7 years of loading. J Periodontol Implant Sci 49: 397 405. [Crossref]

15. Enabulele JE, Omo JO (2016) Socio-demographic determinants of demand for fixed and removable partial dentures. Int J Biomed Health Sci 12: 19-24.

16. Zitzmann NU, Margolin MD, Filippi A, Weiger R, Krastl G (2008) Patient assessment and diagnosis in implant treatment. Aust Dent J 53: S3-S10.

17. Hardt CR, Gröndahl K, Lekholm U, Wennström JL (2002) Outcome of implant therapy in relation to experienced loss of periodontal bone support: a retrospective 5-year study. Clin Oral Implants Res 13: 488-494. [Crossref]

18. Schimmel M, Srinivasan M, McKenna G, Muller F (2018) Effect of advanced age and/or systemic medical conditions on dental implant survival: A systemic review and meta-analysis. Clin Oral Imp Res 29: 311-330. [Crossref]

19. Bornstein MM, Coinca N, Mombelli A (2009) Systemic conditions and treatments as risk for implant therapy. Int J Oral Maxillofac Implants 24: 12-27. [Crossref]

20. Braimoh OB, Alade GO (2019) Prevalence, causes and pattern of tooth loss among elderly people in Port Harcourt, Nigeria. Central Afr J Pub Health 5: 98-101.

21. Enabulele JE, Eregie UJ, Omo JO (2016) Age and gender pattern of partial edentulism. Nig J Restor Dent 1: 32-36.

22. Jung RE, Zembic A, Pjetursson BE, Zwahlen M, Thomas DS (2012) Systematic review of the survival rate and the incidence of biological, technical, and aesthetic complications of single crowns on implants reported in longitudinal studies with a mean follow-up of 5 years. Clin Oral Implants Res 23: 2-21. [Crossref]
23. Levin L, Sadet P, Grossmann Y (2006) A retrospective evaluation of 1,387 single-tooth implants: A 6-year follow-up. J Periodontol 77: 2080-2083. [Crossref]

24. Artziz Tal H, Dyan D (2000) Porous bevine bone marrow in healing of human extraction socket. Part 1. Histomorphometric evaluation at 9 months. J Periodontol 71: 1015-1023.

25. Buser D, Dahlin C, Schenk RK (1994) Guided bone regeneration in implant dentistry. Quintessence publishing co, inc. P32-34.

26. Ciu J, Kerns DG (2014) Mechanisms of guided bone regeneration: A review. Open Dent $J$ 8: 56-65. [Crossref]

27. Dastaran M (2016) A retrospective analysis of grafting and adjunctive procedures performed to facilitate dental implant therapy in private practice. Masters of Philosophy in Dental Science by research. University of Melbourne Dental School.

28. Shenoy VK (2012) Single tooth implants: Pretreatment considerations and pretreatment evaluation. J Interdiscip Dentistry 2: 149-157.

29. Sanivarapu S, Moogla S, Kuntcham RS, Kolaparthy LK (2016) Implant fractures: Rare but not exceptional. J Indian Soc Periodontol 20: 6-11. [Crossref]

30. Hashim D, Ciona N (2020) A comprehensive review of peri-implantitis risk factors Current Oral Health Report 7: 262-273.

31. Berglundh T, Armitage G, Araugo MG, Avila-Ortiz G, Blanco J, et al. (2018) Periimplant diseases and conditions: consensus report of work group 4 of the 2017 world workshop on the classification of periodontal and peri-implant disease and conditions. J Periodontol 89(Suppl 1): S313-S318. [Crossref]

32. Cavalli N, Corbella S, Taschieri S, Francetti L (2015) Prevalence of peri-implant mucositis and peri-implantitis in patients treated with a combination of axial and tilted implants supporting a complete fixed denture. Scien World J 2015: 874842. [Crossref]

33. Montes CC, Pereira FA, Thome G, Alves EDM, Acedo RV, et al. (2007) Failing factors associated with osseointegrated dental implant loss. Implant Dent 6: 404-412. [Crossref]

34. Goodacre CJ, KanJY, Rungcharassaeng K (1999) Clinical complications of osseointegrated implants. J Prosthet Dent 81: 537-552.

35. Wang Y, Zhang Y, Miron RY (2016) Health maintenance and recovery of soft tissue around implants. Clin Implant Dent Related Res 18: 618-634.

36. Romeo E, Storelli S (2012) Systematic review of survival rate and biological, technical and aesthetic complications of fixed dental prostheses with cantilevers on implants reported in longithudinal studies with a mean 5 years follow-up. Clin Oral Implants Res 23: 39-49. [Crossref]

37. Gupta S, Gupta H, Tandan A (2015) Technical complications of implant, causes and management: A comprehensive review. Natl Maxillofac Surg 6: 3-8. [Crossref]

38. Derks J, Schaller D, Hakansson J, Wennstrom JL, Tomasi C, et al. (2016) Effectiveness of implant therapy analyzed in a Swedish population: Prevalence of peri-implantitis. $J$ Dent Res 95: 43-49. [Crossref]

39. French D, Grandin HM, Ofee R (2019) Retrospective cohort study of 4,591 dental implants: Analysis of risk indicators for bone loss and prevalence of peri-implant mucositis and peri-implantitis. J Periodontol 90: 691-700. [Crossref]

40. Koldsland OC, Scheie AA, Aass AM (2010) Prevalence of peri-implantitis related to severity of the disease with different degree of bone loss. J Periodontol 81: 231-238. [Crossref]

41. Wood MR, Vermilyea SG (2004) A review of selected dental literature on evidencebased treatment planning for dental implants: report of the committee on research in fixed prosthodontics. J Prosthet Dent 92: 447-462. [Crossref]

42. Dutta SR, Passi D, Singh P, Atri M, Mohan S, Sharma A (2020) Risks and complications associated with dental implant failure: Critical Update. Natl J Maxillofac Surg 11: 14 19. [Crossref]

43. Becker W, Becker BE, Alsuwyed A, Al-Mubarak S (1999) Long-term evaluation of 282 implants in maxillary and mandibular molar positions: A prospective study. $J$ Periodontol 70: 896-901.

44. Balaguer J, Penarrocha-Oltra D, Penarrocha-Diago M (2015) Long-term survival rates of implants supported overdentures. J Oral Implantol 41: 173-177.

45. Jared F, Romanos GE (2010) The role of primary stability for successful immediate loading of dental implants. A literature review. J Dent 38: 612-620. [Crossref]

46. George A, Khalil A, Hassan N (2015) Comparison between cylinder and tapered implants in delayed immediate placement. Alexandria Dent J 40: 221-228. 
47. Waechter J, Madruja M, Filo LCC, Leite FRM, Schinestsch AR, et al. (2017) Comparison between tapered and cylindrical implants in the posterior region of the mandible: A prospective, randomized, split mouth clinical trial focusing on implant stability changes during early loading. Clinl Implant Dent Related Res 19: 733-741.
48. Alshehri MF, Alshehri F (2016) Influence of implant shape (Taperted $v$ s Cylindrical) on survival of dental implants placed in the posterior maxilla. A systematic review. Implant Dentistry 25: 855-860.

Copyright: (C2021 Agboghoroma OG. This is an open-access article distributed under the terms of the Creative Commons Attribution License, which permits unrestricted use, distribution, and reproduction in any medium, provided the original author and source are credited. 